\title{
Does Personality and Anxiety Symptomatology Matter in the Diabetes Mellitus Treatment Adherence? A Cross -Sectional Study Among Women with Diabetes Mellitus.
}

\author{
Gurpreet Kaur Autar Singh ${ }^{1}$, Luke Sy-Cherng Woon ${ }^{1}$, Hatta Sidi ${ }^{1}$ \\ ${ }^{1}$ Department of Psychiatry, Faculty of Medicine, Universiti Kebangsaan Malaysia, Jalan Yaacob Latif, Kuala Lumpur, Malaysia.
}

\begin{abstract}
INTRODUCTION: Anxiety is prevalent among women with diabetes mellitus (DM). Women also tend to have a higher level of neuroticism. Both underlying neuroticism trait and anxiety symptoms can have an impact on social functioning and diabetes care. This study aimed to determine the relationships between neuroticism and anxiety symptoms, and other clinical and psychosocial variables, among females with DM. MATERIALS AND METHODS: This was a cross-sectional study conducted among women with DM in a Malaysian university hospital. Sociodemographic and clinical variables were acquired, including perceptions on religious practice, social support, and diabetic self-care. Study subjects completed the Generalized Anxiety Disorder 7-item (GAD-7) and the Big-Five Inventory (BFI). The neuroticism subscale of the BFI was used for analysis. RESULTS: There were 141 subjects (Median age: 64.0 years, IQR: 52.5-71.0 years) with a median duration of DM of 12.0 years (IQR: 6.0-20.0 years). Neuroticism scores correlated positively with the GAD-7 scores (Spearman's rho: 0.406; $\mathrm{p}<0.001)$. In bivariate analyses,

Keywords

anxiety; diabetes mellitus; female; neuroticism; personality; self-care

Corresponding Author

Dr Luke Sy-Cherng Woon

Department of Psychiatry

Faculty of Medicine

Universiti Kebangsaan Malaysia

Jalan Yaacob Latif, 56000 Cheras, Kuala

Lumpur, Malaysia.

Tel: +603-91456423

Email: lukewoon@ukm.edu.my

Received: 9 June 2021; Accepted: 4 August 2021

Doi: https://doi.org/10.31436/imjm.v20i4 neuroticism also had significant associations with employment status $(\mathrm{p}=0.023)$, religious practice $(p=0.006)$, perceived social support $(p=0.001)$, and perceived ability of diabetic self-management $(p<0.001)$. In the regression analysis, after controlling for employment, religious practice, and social support, neuroticism remained associated with anxiety $(p<0.001)$ and diabetic self-management $(p=0.001)$. CONCLUSION: Neuroticism was related to a poorer subjective sense of diabetic management and a greater level of anxiety among women with DM. Improving self-efficacy in managing diabetes may help patients coping with anxiety symptoms among those with neuroticism traits, contributing to better treatment among women with DM.
\end{abstract}

\section{INTRODUCTION}

Diabetes mellitus (DM) is one of the most common debilitating chronic conditions leading to decreased quality of life, increasing care cost, and reduction in life expectancy. Worldwide, it was estimated that in 2017, there were 451 million (age 18-99 years) people suffering from DM and it was expected to increase to 693 million by $2045 .{ }^{1} \mathrm{DM}$ is also a key public health concern in Malaysia and is known to increase premature and preventable mortality.

Anxiety is among the highly prevalent mental health conditions, estimated to be affecting 284 million people globally in 2017.2 According to the World Health Organization (WHO), up to $20 \%$ of healthcare attending women in developing countries suffer from anxiety disorders. ${ }^{3}$ $\mathrm{DM}$ is associated with an increased risk of psychological disorders with anxiety being considered as the commonest comorbidity. A large international study involving more than 3000 individuals with type DM from 15 countries reported an overall prevalence of anxiety disorders of $18 \% .{ }^{4}$ Past metaanalysis indicated that patients with DM face a greater likelihood of experiencing anxiety compared to the general population. 5,6

Numerous studies concluded that anxiety symptoms are significantly more prevalent in females compared to males. $4,7,8$ Based on a recent study of 48 reviews, it was revealed that females were almost twice as likely to be affected as males with female: male ratio of 1.9:1. ${ }^{9}$ Anxious individuals were found to have significantly higher mean fasting blood-glucose level comparatively, associated with greater diabetic complications, poorer quality of life with poor treatment adherence, ${ }^{10}$ and higher mortality risk. ${ }^{11}$ 
Neuroticism, one of the domains of the Five-Factor Model of personality, refers to an enduring tendency to experience negative emotions with emotional instability. ${ }^{12,13}$ Individuals scoring high on neuroticism are more susceptible to experience feelings of anxiety, anger, guilt, and depression. It is also well-known that the prevalence of the neuroticism trait is higher in women compared to men. ${ }^{14,15}$

The present work is a part of another study, the Anxiety, Depression, And Personality Traits in Diabetes Mellitus (ADAPT-DM) study carried out at the Universiti Kebangsaan Malaysia Medical Centre, UKMMC. ${ }^{16}$ The main objectives of the present study were: (a) to measure neuroticism trait among female patients with DM; (b) to determine the level of anxiety symptoms; (c) to investigate the relationship between levels of neuroticism with anxiety symptoms, sociodemographic factors, and diabetes-related factors. Based on the available literature, we hypothesized that neuroticism trait is significantly associated with anxiety symptoms, social functioning, and diabetes care.

\section{MATERIALS AND METHODS}

\section{Study Design and Participants}

This was a cross-sectional study conducted at Universiti Kebangsaan Malaysia Medical Centre (UKMMC), a tertiary referral centre in Kuala Lumpur, Malaysia. Approval was obtained from the Research Ethics Committee of Universiti Kebangsaan Malaysia (UKM FPR.SPI 800-2/28/166/FF2019-342). Patients who attended medical outpatient clinics at UKMMC were recruited via convenience sampling. Interested patients were provided with information about the study. Eligible patients had given their informed consent prior to participation in the study. The inclusion criteria for this study were: (1) being 18 years and above, (2) female, and (3) having a confirmed diagnosis of type 1 or type 2 DM. Patients with impaired mental capacity, such as those with active psychosis and dementia, were excluded from the study. As the BFI neuroticism score was the main outcome measurement, the sample size was estimated based on it. Using the standard deviation of 0.6 for the BFI neuroticism score, ${ }^{14}$ with a precision of 0.1 and a confidence interval of $95 \%$, a sample size of 139 was required. ${ }^{17}$

\section{Measuring Instruments}

Study participants were asked to complete a series of questionnaires. Data collected via clinical interview and/or from patient records included: (1): Demographic data (age, race, marital status, employment status, household income, and religion); (2) Social history (practice of religion, perceived level of social support, smoking, and alcohol use); (3) Medical history; (4) DM history (duration, type, and insulin therapy); (5) Body mass index (BMI), classified according to the WHO recommendations for BMI categories in Asian populations; (6) HbA1c levels; and (7) Perceived good self-management of DM (Five-point Likert scale, from 'strongly agree' to 'strongly disagree').

Additional information was collected using validated questionnaires completed by patients at the time of the interview. The following validated instruments in the Malay language were employed: Seven-item Generalised Anxiety Disorder scale (GAD-7): It is a self-reported questionnaire with good reliability, having a sensitivity for diagnosing anxiety (cut point $\geq 8$ ) of $92 \%$ and specificity of $76 \% .{ }^{18}$ The GAD-7 has been found to be a good case-finding instrument for GAD, panic disorder, social anxiety disorder, and post-traumatic stress disorder (PTSD). The Malay version of the GAD-7 was found to be valid and reliable in case-finding for anxiety with good sensitivity of 76\% (95\% CI 61\%-87\%) and specificity of $94 \%(88 \%-97 \%) .{ }^{19}$ Participants with scores $\geq 8$ were classified as having anxiety disorders.

Big Five Inventory (BFI): This is a short instrument to measure the five-factor structure of personality. The BFI includes 44 items divided into five subscales: Extraversion, Agreeableness, Conscientiousness, Neuroticism, and Openness. Participants were asked to select the most relevant response on a 5-point scale: 0-Strongly Agree, 1-Agree, 2-Neutral, 3-Disagree, 4-Strongly Disagree.20 It has been successfully translated into Malay. The Malay version of the BFI showed good internal consistency as well as good convergent and discriminant validity. ${ }^{21}$ Subscal e's scores were calculated based on the answers for analyses.

\section{Data Analysis}

Statistical analysis was carried out using the Statistical Package for Social Science (SPSS), version 20 (IBM Corp., Armonk, NY, USA) software programme. Both GAD-7 and BFI neuroticism scores were not normally distributed (Kolmogorov-Smirnov test: $p<0.001$ for GAD-7 scores and $p=0.006$ for neuroticism scores). Correlation analyses were conducted between BFI neuroticism scores and other continuous variables, including GAD-7 scores, using the Spearman correlation coefficients. BFI neuroticism scores across categorical and ranked variables were analysed using the Mann-Whitney U test (2 categories), Kruskal-Wallis test ( $>2$ categories), and Jonckheere-Terpstra test (ranked 
variables). Multivariate linear regression analysis, including significant variables from univariate analyses, was conducted to determine variables associated with BFI neuroticism scores. Missing values were handled using the listwise deletion method in the regression model.22 All tests were two-tailed. The significance level $(\alpha)$ was set at 0.05 .

\section{RESULTS}

The total number of study participants was 141, with a median age of 64.0 years (IQR: 52.2-71.0 years). Other sociodemographic characteristics of the participants are shown in Table 1. The majority of the participants agreed or strongly agreed that they practised their religion frequently $(84.4 \%)$ and had good social support (82.2\%). With regards to DM, 87.2\% were diagnosed with type 2 DM. The median duration of illness was 12.0 years (IQR: 6.0 - 20.0 years). For the objective measure of diabetic control, the median HbA1c level was $7.5 \%$ (IQR: $6.6 \%-9.3 \%$ ). Subjectively, $74.5 \%$ of the participants agreed or strongly agreed to the statement, 'I am able to manage my diabetes well'. The rates of other medical conditions are given in Table 2 .

The BFI neuroticism scores (Median 2.5, IQR: 2.1 - 2.9) showed a significant correlation with GAD-7 scores (Median 0.0, IQR: $0.0-3.0$ ), but not with other continuous variables (Table 3). When BFI scores were compared across categorical and ranked variables, significant differences were found across categories of employment status $(p=0.023)$, levels of religious practice frequency $(p=0.006)$, levels of social support $(p=0.001)$, and levels of perceived ability for diabetic selfmanagement $(p<0.001)$.

The GAD-7 scores, employment, practice of religion, social support, and perceived ability for diabetic self-management were entered into a multivariate linear regression model for the BFI neuroticism scores (Table 4). While employment, the practice of religion, and social support became statistically insignificant, neuroticism remained associated with the GAD7 scores $(p<0.001)$ and perceived diabetic self-management $(p=0.001)$.
Table 1. Demographic and social variables of the study participants.

\begin{tabular}{|c|c|c|}
\hline Variables & $\mathrm{N}$ & $\%$ \\
\hline \multicolumn{3}{|l|}{ Race } \\
\hline Malay & 99 & 70.2 \\
\hline Chinese & 23 & 16.3 \\
\hline Indian & 17 & 12.1 \\
\hline Others & 2 & 1.4 \\
\hline \multicolumn{3}{|l|}{ Marital status } \\
\hline Married & 89 & 63.1 \\
\hline Single & 17 & 12.1 \\
\hline Divorced/separated & 4 & 2.8 \\
\hline Widowed & 30 & 21.3 \\
\hline Missing & 1 & 0.7 \\
\hline \multicolumn{3}{|l|}{ Employment } \\
\hline Employed & 59 & 41.8 \\
\hline Unemployed & 35 & 24.8 \\
\hline Retired & 45 & 31.9 \\
\hline Missing & 2 & 1.4 \\
\hline \multicolumn{3}{|l|}{ Household income } \\
\hline$<\mathrm{RM} 3,000$ & 92 & 65.2 \\
\hline RM3,000-6,000 & 27 & 19.1 \\
\hline$>\mathrm{RM} 6,000$ & 16 & 11.3 \\
\hline Missing & 6 & 4.3 \\
\hline \multicolumn{3}{|l|}{ Religion } \\
\hline Islam & 101 & 71.6 \\
\hline Buddhism & 17 & 12.1 \\
\hline Hinduism & 15 & 10.6 \\
\hline Christianity & 6 & 4.3 \\
\hline Others & 1 & .7 \\
\hline Missing & 1 & 0.7 \\
\hline \multicolumn{3}{|l|}{ Frequently practise religion } \\
\hline Strongly disagree & 3 & 2.1 \\
\hline Disagree & 4 & 2.8 \\
\hline Neutral & 15 & 10.6 \\
\hline Agree & 66 & 46.8 \\
\hline Strongly agree & 53 & 37.6 \\
\hline \multicolumn{3}{|l|}{ Have good social support } \\
\hline Strongly disagree & 0 & 0 \\
\hline Disagree & 5 & 3.5 \\
\hline Neutral & 20 & 14.2 \\
\hline Agree & 90 & 63.8 \\
\hline Strongly agree & 26 & 18.4 \\
\hline \multicolumn{3}{|l|}{ Smoking } \\
\hline Never & 137 & 97.2 \\
\hline Ex-smoker & 3 & 2.1 \\
\hline Current smoker & 1 & .7 \\
\hline \multicolumn{3}{|l|}{ Alcohol use } \\
\hline Yes & 2 & 1.4 \\
\hline No & 139 & 98.6 \\
\hline
\end{tabular}


Table 2. Diabetes-related and other clinical variables.

\begin{tabular}{|c|c|c|}
\hline Variables & $\mathrm{N}$ & $\%$ \\
\hline \multicolumn{3}{|l|}{ DM type } \\
\hline Type 1 & 10 & 7.1 \\
\hline Type 2 & 123 & 87.2 \\
\hline Gestational & 6 & 4.3 \\
\hline Missing & 2 & 1.4 \\
\hline \multicolumn{3}{|l|}{ Insulin therapy } \\
\hline Yes & 72 & 51.1 \\
\hline No & 53 & 37.6 \\
\hline Missing & 16 & 11.3 \\
\hline \multicolumn{3}{|c|}{ 'I am able to manage my diabetes well' } \\
\hline Strongly disagree & 1 & 0.7 \\
\hline Disagree & 5 & 3.5 \\
\hline Neutral & 29 & 20.6 \\
\hline Agree & 55 & 39.0 \\
\hline Strongly agree & 50 & 35.5 \\
\hline Missing & 1 & 0.7 \\
\hline \multicolumn{3}{|l|}{ Obesity } \\
\hline $\mathrm{BMI}<23.0 \mathrm{~kg} / \mathrm{m}^{2}$ & 21 & 14.9 \\
\hline BMI $23.0-27.5 \mathrm{~kg} / \mathrm{m}^{2}$ & 27 & 19.1 \\
\hline $\mathrm{BMI}>27.5 \mathrm{~kg} / \mathrm{m}^{2}$ & 53 & 37.6 \\
\hline Missing & 40 & 28.4 \\
\hline \multicolumn{3}{|l|}{ Hypertension } \\
\hline Yes & 106 & 75.2 \\
\hline No & 35 & 24.8 \\
\hline \multicolumn{3}{|l|}{ Dyslipidaemia } \\
\hline Yes & 76 & 53.9 \\
\hline No & 65 & 46.1 \\
\hline \multicolumn{3}{|l|}{ Ischaemic heart disease } \\
\hline Yes & 26 & 18.4 \\
\hline No & 115 & 81.6 \\
\hline \multicolumn{3}{|l|}{ Stroke } \\
\hline Yes & 10 & 7.1 \\
\hline No & 131 & 92.9 \\
\hline \multicolumn{3}{|l|}{ Renal disease } \\
\hline Yes & 22 & 15.6 \\
\hline No & 119 & 84.4 \\
\hline
\end{tabular}

As the study included participants with various subtypes of $\mathrm{DM}$, additional subgroup analyses were conducted for subjects with type $2 \mathrm{DM}$ only $(\mathrm{N}=123)$ to check the validity of the findings. The results of these bivariate analyses and multivariate linear regression analysis are presented in the Supplementary Tables (Tables S1 - S3). The findings were largely similar to the main analyses, with the linear regression model producing the same significant associations between neuroticism and GAD-7 scores as well as perceived diabetic self-management (Table S3).
Table 3. BFI neuroticism scores across sociodemographic and clinical variables.

\begin{tabular}{|c|c|c|c|c|}
\hline \multirow{2}{*}{ Variables } & & \multicolumn{2}{|c|}{ BFI neuroticism score } & \multirow{2}{*}{$p$-value } \\
\hline & & Median & IQR & \\
\hline \multirow[t]{5}{*}{ Race $^{a}$} & & & & 0.069 \\
\hline & Malay & 2.38 & 0.8 & \\
\hline & Chinese & 2.75 & 0.88 & \\
\hline & Indian & 2.75 & 0.75 & \\
\hline & Others & 2.26 & NA & \\
\hline \multicolumn{4}{|c|}{ Marital status ${ }^{\mathrm{a}}$} & 0.849 \\
\hline & Married & 2.5 & 0.87 & \\
\hline & Single & 2.57 & 1.07 & \\
\hline & Divorced/separated & 2.13 & NA & \\
\hline & Widowed & 2.5 & 0.6 & \\
\hline \multicolumn{4}{|c|}{ Employment $^{\mathrm{a}}$} & $0.023^{*}$ \\
\hline & Employed & 2.75 & 0.88 & \\
\hline & Unemployed & 2.5 & 0.6 & \\
\hline & Retired & 2.25 & 0.71 & \\
\hline \multicolumn{4}{|c|}{ Household income ${ }^{b}$} & 0.128 \\
\hline & $<\mathrm{RM} 3,000$ & 2.62 & 0.67 & \\
\hline & RM3,000-6,000 & 2.38 & 1 & \\
\hline & $>\mathrm{RM} 6,000$ & 2.38 & 0.94 & \\
\hline \multicolumn{4}{|l|}{ Religion ${ }^{a}$} & 0.051 \\
\hline & Islam & 2.38 & 0.73 & \\
\hline & Buddhism & 2.82 & 0.69 & \\
\hline & Hindusim & 2.75 & 0.91 & \\
\hline & Christianity & 2.88 & 1.41 & \\
\hline & Others & 0 & NA & \\
\hline Frequently & ractise religion ${ }^{\mathrm{b}}$ & & & $0.006^{*}$ \\
\hline & Strongly disagree & 3 & NA & \\
\hline & Agree & 2.69 & 0.32 & \\
\hline & Neutral & 2.69 & 0.75 & \\
\hline & Agree & 2.38 & 0.84 & \\
\hline & Strongly agree & 2.4 & 0.92 & \\
\hline Have good & ocial support ${ }^{\mathrm{b}}$ & & & $0.001 *$ \\
\hline & Strongly disagree & $\mathrm{NA}$ & NA & \\
\hline & Agree & 2.5 & 0.34 & \\
\hline & Neutral & 2.8 & 0.75 & \\
\hline & Agree & 2.5 & 0.87 & \\
\hline & Strongly agree & 2.13 & 0.88 & \\
\hline Smokinga & & & & 0.967 \\
\hline & Never & 2.5 & 0.78 & \\
\hline & Ex-smoker & 2.5 & NA & \\
\hline & Current smoker & 0 & $\mathrm{NA}$ & \\
\hline Alcohol us & & & & 0.843 \\
\hline & Yes & 0 & NA & \\
\hline & No & 2.5 & 0.75 & \\
\hline Insulin the & & & & 0.885 \\
\hline & Yes & 2.44 & 0.88 & \\
\hline & No & 2.45 & 0.76 & \\
\hline 'I am able & manage my diabetes we & & & $<0.001^{*}$ \\
\hline & Strongly disagree & NA & $\mathrm{NA}$ & \\
\hline & Disagree & 3 & NA & \\
\hline & Neutral & 2.63 & 0.72 & \\
\hline & Agree & 2.5 & 0.78 & \\
\hline & Strongly agree & 2.25 & 1 & \\
\hline Obesity & & & & \\
\hline & $\mathrm{BMI}<23.0 \mathrm{~kg} / \mathrm{m}^{2}$ & 2.25 & 1.25 & 0.395 \\
\hline & BMI $23.0-27.5 \mathrm{~kg} / \mathrm{m}^{2}$ & 2.38 & 0.87 & \\
\hline & $\mathrm{BMI}>27.5 \mathrm{~kg} / \mathrm{m}^{2}$ & 2.63 & 0.65 & \\
\hline Hypertensi & & & & 0.384 \\
\hline & Yes & 2.44 & 0.82 & \\
\hline & No & 2.45 & 0.95 & \\
\hline Dyslipidaer & & & & 0.952 \\
\hline & Yes & 2.25 & 0.76 & \\
\hline & No & 2.5 & 0.75 & \\
\hline Ischaemic & eart disease ${ }^{c}$ & & & 0.054 \\
\hline & Yes & 2.44 & 0.73 & \\
\hline & No & 2.45 & 0.75 & \\
\hline Strokec & & & & 0.684 \\
\hline & Yes & 2.13 & 0.75 & \\
\hline & No & 2.5 & 0.88 & \\
\hline Renal disea & & & & 0.966 \\
\hline & Yes & 2.63 & 0.56 & \\
\hline & No & 2.4 & 0.88 & \\
\hline Variable & Spearman': & orrelation $\mathrm{c}$ & & $p$-value \\
\hline Age & & 0.084 & & 0.324 \\
\hline $\begin{array}{l}\text { Duration } \\
\text { of DM }\end{array}$ & & 0.073 & & 0.418 \\
\hline $\mathrm{HbA1c}$ & & -0.012 & & 0.894 \\
\hline $\begin{array}{l}\text { G A D - } 7 \\
\text { scores }\end{array}$ & & 0.406 & & $<0.001^{*}$ \\
\hline
\end{tabular}


Table 4. Multivariate linear regression for variables associated with BFI neuroticism scores.

\begin{tabular}{|c|c|c|c|c|}
\hline \multirow{2}{*}{ Variable } & \multirow{2}{*}{ Coefficient } & \multicolumn{2}{|c|}{$95 \% \mathrm{CI}$} & \multirow{2}{*}{$p$-value } \\
\hline & & Lower & Upper & \\
\hline GAD-7 scores & 0.052 & 0.030 & 0.075 & $\begin{array}{c}<0.001 \\
*\end{array}$ \\
\hline Employment & -0.058 & -0.151 & 0.035 & 0.221 \\
\hline $\begin{array}{l}\text { Practice of } \\
\text { religion }\end{array}$ & -0.084 & -0.185 & 0.017 & 0.104 \\
\hline Social support & -0.066 & -0.197 & 0.064 & 0.317 \\
\hline $\begin{array}{l}\text { 'I am able to } \\
\text { manage my } \\
\text { diabetes well' }\end{array}$ & -0.167 & -0.259 & -0.074 & $0.001 *$ \\
\hline
\end{tabular}

$F(5,132)=11.951, p<0.001, R^{2}=0.312$

$*$ Statistically significant

\section{DISCUSSION}

The present study revealed no association between neuroticism and objective measures of diabetic control. However, neuroticism was related to a poorer subjective sense of diabetic management and a greater level of anxiety among females with DM.

In this study, the presence of neuroticism trait was found to correlate with anxiety symptoms. Most studies show strong association between neuroticism and anxiety suggesting that the neuroticism trait itself predisposes to the emergence of anxiety symptoms. ${ }^{6,23}$. High neuroticism trait leads to negative emotions such as worry, fear, depression, etc., predisposing to anxiety. In certain conditions, an individual with neuroticism trait tends to experience such intense negative emotions especially when stressors are not well managed, eventually leading to poorer outcome. ${ }^{24,25}$

Compared to other personality traits, neuroticism was shown to be a strong predictor of psychopathology. It is evident that anxiety is closely associated with neuroticism traits 7,26 emerging as a vulnerability factor for the development of anxiety. ${ }^{27,28}$ According to Aldinger et al. (2004), nervous and emotionally unstable individuals were at a 7 -fold increased risk of developing anxiety disorders comparatively. ${ }^{27}$

Out of the five dimensions of the Five-Factor Model, neuroticism being the factor of interest in this study was due to its strong and thoroughly researched association with anxiety. ${ }^{26}$ Neuroticism is linked to many different psychopathologies where anxiety may play a role. The synergistic relationship between neuroticism trait and internalizing psychopathologies especially anxiety disorders are well known. ${ }^{29}$ Similarly, another study indicated that anxiety had a strong, positive association with neuroticism whereby women reported higher levels of anxiety and neuroticism compared to men. ${ }^{30}$ Women were known to be more prevalently anxious in view of their different coping skills used to overcome stressors, predicting the presence of high anxiety traits. ${ }^{31}$

One of the possible mechanisms includes the mediating effects of rumination and worry. Rumination, which is described as unproductive, repetitive negative thoughts, is considered as a psychological vulnerability to anxiety. ${ }^{32-34}$ In their study of 405 elderly adults from China, Chen et al. found that neuroticism was found to be significantly linked to symptoms of anxiety. Furthermore, mediation analysis demonstrated that this relationship was partially mediated by rumination. ${ }^{33}$ Hence, patients with a greater degree of neuroticism may be more likely to be ruminative. As they are prone to be preoccupied with negative life events, they may experience more severe anxiety.

Our study findings conform with the stress-diathesis model, which proposes that for individuals with high levels of neuroticism, exposure to difficult life events contributes to the emergence of anxiety symptoms. ${ }^{35}$ As for the current study, females with higher neuroticism traits when diagnosed with DM are more likely to experience ruminative thoughts and worries concerning their illness. And when these thoughts are manifested intensely it may result in heightened anxiety and a poor subjective sense of illness management.

Genetic studies have postulated that higher neuroticism score causes anxiety and other psychological disorders. ${ }^{36-39}$ Hettema et al. performed the largest population-based twin study on this topic to date. They gauged data from over 9000 male and female twins, discovered $40-50 \%$ genetic correlations between neuroticism and anxiety disorders with low environmental correlations, concluding that the association between neuroticism and anxiety disorder is essentially caused by their mutual genetic factors. ${ }^{40}$

Numerous studies have reported the link between personality domains and physical health. 13,41,42 Among the personality traits, neuroticism appears to be robustly associated with a broader range of physical health problems, including DM. ${ }^{43-45}$ In a study by Wheeler et al. in 2012, high neuroticism was significantly related to lesser adherence to their diabetes regimen, including diet, exercise, and glycaemic control. ${ }^{44}$ On the contrary, another large prospective study by Cukić and Weiss found that higher levels of neuroticism were associated with reduced risk of type $2 \mathrm{DM}$, after controlling for confounders such as age, race, BMI, and depressive symptoms. This is attributed to the association between neuroticism and greater vigilance and perceived susceptibility to health risks, leading to early help-seeking behaviour. ${ }^{43}$ Such contradictory findings suggest that there might be unknown 
variables affecting the relationship between neuroticism traits and diabetes care-related behaviours, which warrant further investigation.

Self-efficacy is concerned with the judgments on how well one can execute courses of action required to deal with prospective situations. 46 When a self-efficacious person is faced with difficulties, they tend to exert greater effort to master the challenges compared to those who have serious doubts about their capabilities who tend to exert lesser effort leading to giving up altogether. ${ }^{46}$ Evidence has shown a strong significant negative relationship between self-efficacy and neuroticism. ${ }^{47,48} \mathrm{~A}$ recent meta-analysis of 53 studies reported that neuroticism was strongly and consistently correlated negatively with self-efficacy, in contrast to all other Big Five Traits that demonstrated positive correlations. ${ }^{49}$

The present study reveals the inverse relationship between neuroticism trait and self-efficacious behaviour in diabetic care. Individuals with neuroticism trait displayed a lower level of self-efficacy when it comes to managing their illness. Selfcare in DM is crucial when it comes to the management of their illness. Though this study is parallel to other studies in having a lack of any relationship between the objective outcome of diabetes, ${ }^{50}$ it appears that subjectively the neuroticism trait does play a role. Individuals with higher neuroticism scores are least confident in carrying out healthy behaviours in alleviating their symptoms, such as adhering to healthy dietary habits and regular exercise behaviours.44,51 Besides that, these individuals also showed a pessimistic attitude when it came to engaging in positive behaviour in managing their own health. ${ }^{51}$

Another vital factor includes non-adherence to the treatment, which is described as taking $<80 \%$ of the prescribed treatment. ${ }^{52}$ The prevalence of non-adherence to DM medications was noted to be $30 \% .52$ Neuroticism was significantly related to adherence. The more neurotic the individual was, the less their adherence to the treatment, supporting that personality factors in chronically ill individuals may affect their illness care and outcome.44 Our study highlights that neuroticism is an important variable to consider in the context of the patient's diabetes adherence. These findings could influence diabetes intervention and care in several ways such as treatment adherence, diet control, and exercise. $^{44}$

This study had few limitations. Firstly, this study being crosssectional in nature was not able to establish causal relationships. As both exposure and outcome are simultaneously assessed, there is no evidence of a temporal relationship between neuroticism and anxiety. Hence, without a longitudinal data, it is not feasible to determine a true cause-and-effect relationship in the absence of follow-up care. Another limitation of this study is about the small sample size, which was carried out conveniently in a tertiary care centre. However, it is believed that the findings can be generalised in the Malaysian context in view of similarity of participants' socio-demographic characteristics with the general population of Malaysia. The use of single-question assessments in this study might also have contributed to a possible limitation as validated scales were not employed to evaluate social support, diabetic self-management, and religious practice.

Despite these limitations, this present study contributes to the understanding of the relationship between neuroticism and anxiety among female patients with DM, as studies in Malaysia are scant and only reported the magnitude of the psychopathology in DM. 52 Further longitudinal studies with follow-up care and assessment is suggested to investigate the true causal relationship between the variables. Besides that, a multi-site study with stratified random sampling is proposed as it provides better coverage of the population to strengthen the representation of the data.

\section{CONCLUSIONS}

Our study showed that neuroticism traits were associated with a poorer subjective sense of DM management. A greater level of intervention is pivotal to increase the self-efficacy in managing patients with DM by modifying the neuroticism traits which may help in reducing their anxiety symptoms. Eventually, this may improve the sense well-being and better treatment outcomes.

\section{Data Availability}

The data used to support the findings of this study is available upon request from the corresponding author.

\section{Conflict of Interest}

The authors declare that there is no conflict of interest regarding the publication of this paper.

\section{Authors' Contributions}

Gurpreet Kaur Autar Singh wrote the main manuscript text. Luke Sy-Cherng Woon and Hatta Sidi conceived and designed the study. Luke Sy-Cherng Woon analyzed the data. Luke Sy-Cherng Woon and Hatta Sidi reviewed and interpreted the results and assisted in the writing of the manuscript. All authors have read and agreed to the published version of the manuscript. 


\section{Funding Statement}

This research was supported by the Young Lecturers Incentive Grant (GGPM-2019-024) from the Research University Fund of the Universiti Kebangsaan Malaysia.

\section{ACKNOWLEDGMENTS}

The authors would like to express their gratitude to Paula Junggar Gosse, Emily Samantha Kaunismaa, and Roslyn Laurie Mainland from the University of Toronto for their significant contribution to data collection for the ADAPTDM study.

\section{Supplementary Materials}

The Supplementary Tables (S1 - S3) contain results of subgroup analyses for study subjects with type $2 \mathrm{DM}$ only.

Table S1. Correlations between BFI neuroticism scores and other continuous variables.

\begin{tabular}{lcc}
\hline Variable & $\begin{array}{c}\text { Spearman's correlation } \\
\text { coefficient }\end{array}$ & $p$-value \\
\hline Age & 0.012 & 0.898 \\
Duration of DM & 0.112 & 0.239 \\
HbA1c & 0.048 & 0.610 \\
GAD-7 scores & 0.401 & $<0.001 *$ \\
\hline
\end{tabular}

* Statistically significant

Table S2. BFI neuroticism scores across categorical and ranked variables.

\begin{tabular}{|c|c|}
\hline Variables & $p$-value \\
\hline Race $^{\mathrm{a}}$ & 0.058 \\
\hline Marital status ${ }^{a}$ & 0.633 \\
\hline Employment ${ }^{\mathrm{a}}$ & $0.024 *$ \\
\hline Household income ${ }^{b}$ & 0.778 \\
\hline Religion $^{\mathrm{a}}$ & $0.038^{*}$ \\
\hline Frequently practise religion ${ }^{b}$ & $0.013^{*}$ \\
\hline Have good social support ${ }^{b}$ & $0.003^{*}$ \\
\hline Smokinga & 0.751 \\
\hline Alcohol use ${ }^{c}$ & 0.894 \\
\hline Insulin therapyc & 0.418 \\
\hline 'I am able to manage my diabetes well' & $0.004^{*}$ \\
\hline \multicolumn{2}{|l|}{ Obesityb } \\
\hline Hypertension ${ }^{c}$ & 0.680 \\
\hline Dyslipidaemiac & 0.821 \\
\hline Ischaemic heart disease $^{c}$ & 0.080 \\
\hline Strokec & 0.819 \\
\hline Renal disease ${ }^{c}$ & 0.729 \\
\hline
\end{tabular}

Table S3. Multivariate linear regression for variables associated with BFI neuroticism scores.

\begin{tabular}{lcccc}
\hline \multirow{2}{*}{ Variable } & Coefficient & \multicolumn{2}{c}{$95 \%$ CI } & \multirow{2}{*}{$p$-value } \\
\cline { 3 - 4 } & & Lower & Upper & \\
\hline GAD-7 scores & 0.334 & 0.026 & 0.076 & $<0.001^{*}$ \\
Employment & -0.105 & -0.164 & 0.035 & 0.200 \\
Religion & 0.109 & -0.040 & 0.175 & 0.215 \\
Practice of religion & -0.073 & -0.171 & 0.079 & 0.465 \\
Social support & -0.112 & -0.225 & 0.055 & 0.232 \\
$\begin{array}{l}\text { 'I am able to manage } \\
\text { my diabetes well' }\end{array}$ & -0.218 & -0.238 & -0.034 & $0.009 *$ \\
\hline
\end{tabular}

$F(6,119)=8.286, p<0.001, R^{2}=0.307$

* Statistically significant

\section{REFERENCES}

1. Cho NH, Shaw JE, Karuranga S, et al. IDF Diabetes Atlas: Global estimates of diabetes prevalence for 2017 and projections for 2045. Diabetes Research and Clinical Practice. 2018; 138:271-81.

2. Our World in Data. Mental Health. https:// ourworldindata.org/mental-health. Accessed December 8, 2020.

3. World Health Organization. Mental Health and Substance Use. https://www.who.int/teams/mentalhealth-and-substance-use/gender-and-women-s-mentalhealth. Accessed December 8, 2020.

4. Chaturvedi SK, Manche Gowda S, Ahmed HU, et al. More anxious than depressed: prevalence and correlates in a 15-nation study of anxiety disorders in people with type 2 diabetes mellitus. Gen Psychiatr. 2019; 32:e100076.

5. Smith KJ, Béland M, Clyde M, et al. Association of diabetes with anxiety: A systematic review and metaanalysis. Journal of Psychosomatic Research. 2013; 74:8999.

6. Vittengl JR. Who pays the price for high neuroticism? Moderators of longitudinal risks for depression and anxiety. Psychological Medicine. 2017; 47:1794-805.

7. Gao W, Ping S, Liu X. Gender differences in depression, anxiety, and stress among college students: A longitudinal study from China. Journal of Affective Disorders. 2020; 263:292-300.

8. McLean CP, Asnaani A, Litz BT, Hofmann SG. Gender differences in anxiety disorders: prevalence, course of illness, comorbidity and burden of illness. Journal of Psychiatric Research. 2011; 45:1027-35.

9. Remes O, Brayne C, Van Der Linde R, Lafortune L. A systematic review of reviews on the prevalence of anxiety disorders in adult populations. Brain and Behavior. 2016; 6:497. 
10. Saleh F, Mumu SJ, Ara F, Hafez MA, Ali L. Nonadherence to self-care practices $\&$ medication and health related quality of life among patients with type 2 diabetes: a cross-sectional study. BMC Public Health. 2014; 14:431.

11. Naicker K, Johnson JA, Skogen JC, et al. Type 2 diabetes and comorbid symptoms of depression and anxiety: Longitudinal associations with mortality risk. Diabetes Care. 2017; 40:352-8.

12. Ormel J, Jeronimus BF, Kotov R, et al. Neuroticism and common mental disorders: meaning and utility of a complex relationship. Clinical Psychology Review. 2013; 33:686-97.

13. Tackett JL, Lahey BB. Neuroticism. In: Widiger TA, ed. The Oxford Handbook of the Five Factor Model. Oxford: Oxford University Press, 2017: 39-56.

14. Weisberg YJ, Deyoung CG, Hirsh JB. Gender Differences in Personality across the Ten Aspects of the Big Five. Frontiers in Psychology. 2011; 2:178.

15. Vianello M, Schnabel K, Sriram N, Nosek B. Gender differences in implicit and explicit personality traits. Personality and Individual Differences. 2013; 55:994-9.

16. Woon LSC, Sidi H, Ravindran A, et al. Depression, anxiety, and associated factors in patients with diabetes: Evidence from the anxiety, depression, and personality traits in diabetes mellitus (ADAPT-DM) study. BMC Psychiatry. 2020; 20:227.

17. Hajian-Tilaki K. Sample size estimation in epidemiologic studies. Caspian Journal of Internal Medicine. 2011; 2:289-98.

18. Spitzer RL, Kroenke K, Williams JBW, Löwe B. A brief measure for assessing generalized anxiety disorder: The GAD-7. Archives of Internal Medicine. 2006; 166:10927.

19. Sidik SM, Arroll B, Goodyear-Smith F. Validation of the GAD-7 (Malay version) among women attending a primary care clinic in Malaysia. Journal of Primary Health Care. 2012; 4:5-11.

20. John OP, Donahue EM, Kentle RL. The Big Five Inventory -Versions $4 \mathrm{a}$ and 54. Berkeley, CA: University of California, Berkeley, Institute of Personality and Social Research, 1991.

21. Muhamad H, Roodenburg J, Moore DW. The adaptation of the Big Five Inventory in measuring Malaysian youths' personality traits. International Journal of Advanced and Applied Sciences. 2018; 5:814.

22. Meeyai S. Logistic regression with missing data: a comparison of handling methods, and effects of percent missing values. Journal of Traffic and Logistics Engineering. 2016; 4:128-34.
23. Zinbarg RE, Mineka S, Bobova L, et al. Testing a hierarchical model of neuroticism and its cognitive facets. Clinical Psychological Science. 2016; 4:805-24.

24. Afshar H, Roohafza HR, Keshteli AH, et al. The association of personality traits and coping styles according to stress level. Journal of Research in Medical Sciences. 2015; 20:353-8.

25. Hao R, Dong H, Zhang R, et al. The Relationship Between Neuroticism Fit and General Well-Being: The Mediating Effect of Psychological Resilience. Frontiers in Psychology. 2019; 10:2219.

26. Grav S, Stordal E, Romild UK, Hellzen O. The relationship among neuroticism, extraversion, and depression in the HUNT Study: in relation to age and gender. Issues in Mental Health Nursing. 2012; 33:77785.

27. Aldinger M, Stopsack M, Ulrich I, et al. Neuroticism developmental courses - implications for depression, anxiety and everyday emotional experience; a prospective study from adolescence to young adulthood. BMC Psychiatry. 2014; 14:210.

28. Paulus DJ, Vanwoerden S, Norton PJ, Sharp C. From neuroticism to anxiety: Examining unique contributions of three transdiagnostic vulnerability factors.

Personality and Individual Differences. 2016; 94:38-43.

29. Hyatt CS, Owens MM, Gray JC, et al. Personality traits share overlapping neuroanatomical correlates with internalizing and externalizing psychopathology. Journal of Abnormal Psychology. 2019; 128:1-11.

30. Johansson M, Ölund A. Thinking about thinking: A study of anxiety, neuroticism and need for cognition. [Online] [Dissertation]. 2017. Available at: http:// urn.kb.se/resolve?urn=urn:nbn:se:umu:diva $-135853</$ div >. Accessed December 8, 2020.

31. Bale TL, Epperson CN. Sex differences and stress across the lifespan. Nature Neuroscience. 2015; 18:1413-20.

32. Denovan A, Dagnall N, Lofthouse G. Neuroticism and Somatic Complaints: Concomitant Effects of Rumination and Worry. Behavioural and Cognitive Psychotherapy. 2019; 47:431-45.

33. Chen X, Pu J, Shi W, Zhou Y. The impact of neuroticism on symptoms of anxiety and depression in elderly adults: the mediating role of rumination.

Current Psychology. 2020; 39:42-50.

34. Merino H, Senra C, Ferreiro F. Are worry and rumination specific pathways linking neuroticism and symptoms of anxiety and depression in patients with generalized anxiety disorder, major depressive disorder and mixed anxiety-depressive disorder? PLoS One. 2016; 11:e0156169. 
35. Ormel J, Jeronimus BF, Kotov R, et al. Neuroticism and common mental disorders: Meaning and utility of a complex relationship. Clinical Psychology Review. 2013; 33:686-97.

36. Hansell NK, Wright MJ, Medland SE, et al. Genetic co -morbidity between neuroticism, anxiety/depression and somatic distress in a population sample of adolescent and young adult twins. Psychological Medicine. 2012; 42:1249-60.

37. Golimbet VE, Volel BA, Korovaitseva GI, et al. Association of inflammatory genes with neuroticism, anxiety and depression in male patients with coronary heart disease. Zhurnal Nevrologii i Psikhiatrii imeni S.S. Korsakova. 2017; 117:74-9.

38. Okbay A, Baselmans BM, De Neve JE, et al. Genetic variants associated with subjective well-being, depressive symptoms, and neuroticism identified through genome-wide analyses. Nature Genetics. 2016; 48:624-33.

39. Mandelli L, Antypa N, Nearchou FA, et al. The role of serotonergic genes and environmental stress on the development of depressive symptoms and neuroticism. Journal of Affective Disorders. 2012; 142:82-9.

40. Hettema JM, Neale MC, Myers JM, Prescott CA, Kendler KS. A population-based twin study of the relationship between neuroticism and internalizing disorders. American Journal of Psychiatry. 2006; 163:857-64.

41. Hagger-Johnson G, Roberts B, Boniface D, et al. Neuroticism and cardiovascular disease mortality: socioeconomic status modifies the risk in women (UK Health and Lifestyle Survey). Psychosomatic Medicine. 2012; 74:596-603.

42. Friedman HS, Kern ML. Personality, well-being, and health. Annual Review of Psychology. 2014; 65:719-42.

43. Cukić I, Weiss A. Personality and diabetes mellitus incidence in a national sample. Journal of Psychosomatic Research. 2014; 77:163-8.

44. Wheeler K, Wagaman A, McCord D. Personality traits as predictors of adherence in adolescents with type I diabetes. Journal of Child and Adolescent Psychiatric Nursing. 2012; 25:66-74.

45. Friedman HS. Neuroticism and health as individuals age. Personality Disorders. 2019; 10:25-32.

46. Reisi M, Mostafavi F, Javadzade H, et al. Impact of Health Literacy, Self-efficacy, and Outcome Expectations on Adherence to Self-care Behaviors in Iranians with Type 2 Diabetes. Oman Medical Journal. 2016; 31:52-9.

47. Zhang G, Chen X, Xiao L, et al. The relationship between Big Five and self-control in boxers: a mediating model. Frontiers in Psychology. 2019; 10:1690.

48. Şahin F, Çetin F. The mediating role of general selfefficacy in the relationship between the Big Five Personality traits and perceived stress: a weekly assessment study. Psychological Studies. 2017; 62:3546.

49. Barańczuk U. 2021. The Five-Factor Model of personality and generalized self efficacy: A metaanalysis. Journal of Individual Differences. 2021. Advance online publication. Available at: https:/ / doi.org/10.1027/1614-0001/a000345

50. Dehghan H, Charkazi A, Kouchaki GM, et al. General self-efficacy and diabetes management self-efficacy of diabetic patients referred to diabetes clinic of Aq Qala, North of Iran. Journal of Diabetes \& Metabolic Disorders. 2017;16:8.

51. Novak JR, Anderson JR, Johnson MD, et al. Does personality matter in diabetes adherence? Dxploring the pathways between neuroticism and patient adherence in couples with type 2 diabetes. Applied Psychology: Health and Well-Being. 2017; 9:207-27.

52. Kassahun A, Gashe F, Mulisa E, Rike WA. Nonadherence and factors affecting adherence of diabetic patients to anti-diabetic medication in Assela General Hospital, Oromia Region, Ethiopia. Journal of Pharmacy and Bioallied Sciences. 2016; 8:124-9.

53. Kaur G, Tee GH, Ariaratnam S, Krishnapillai AS, China K. Depression, anxiety and stress symptoms among diabetics in Malaysia: a cross sectional study in an urban primary care setting. BMC Family Practice. 2013; 14:69. 